\title{
Intakes and breast-milk concentrations of essential fatty acids are low among Bangladeshi women with 24-48-month-old children
}

\author{
Elizabeth A. Yakes ${ }^{1,2 *}$, Joanne E. Arsenault ${ }^{1}$, M. Munirul Islam ${ }^{3}$, Mohammad B. Hossain ${ }^{3}$, \\ Tahmeed Ahmed ${ }^{3}$, J. Bruce German ${ }^{4}$, Laura A. Gillies ${ }^{4}$, Ahmed Shafiqur Rahman ${ }^{3}$, Christiana Drake ${ }^{2,5}$, \\ Kazi M. Jamil ${ }^{3}$, Bess L. Lewis ${ }^{6}$ and Kenneth H. Brown ${ }^{1,2}$ \\ ${ }^{1}$ Department of Nutrition, University of California, One Shields Avenue, Davis, CA 95616, USA \\ ${ }^{2}$ Graduate Group in Epidemiology, University of California, Davis, CA 95616, USA \\ ${ }^{3}$ International Centre for Diarrhoeal Disease Research (ICDDR,B), Dhaka, Bangladesh \\ ${ }^{4}$ Department of Food Science and Technology, University of California, Davis, CA 95616, USA \\ ${ }^{5}$ Department of Statistics, University of California, Davis, CA 95616, USA \\ ${ }^{6}$ International Agricultural Development Graduate Group, University of California, Davis, CA 95616, USA
}

(Received 17 May 2010 - Revised 26 October 2010-Accepted 1 November 2010-First published online 16 February 2011)

\begin{abstract}
Maternal fat intake and adipose reserves are major sources of PUFA during lactation. The present study examined the cross-sectional relationship between prolonged breast-feeding and maternal BMI, assessed adequacy of fat intake among lactating and non-lactating mothers of children 24-48 months of age and determined breast-milk fatty acid composition. Multi-stage sampling was used to select a representative sample of mothers from two rural districts in Bangladesh ( $n$ 474). Dietary data were collected during two non-consecutive $24 \mathrm{~h}$ periods via $12 \mathrm{~h}$ in-home daytime observations and recall. The National Cancer Institute method for episodically consumed foods was used to estimate usual intake distributions. Breast milk samples were collected from ninety-eight women, and breast-milk fatty acid methyl esters were quantified using GC. Approximately $42 \%$ of lactating $v .26 \%$ of non-lactating mothers were underweight (BMI $<18.5 \mathrm{~kg} / \mathrm{m}^{2}$; $P=0.0003$ ). The maternal diet was low in total fat (approximately $8 \%$ of mean total energy) and food sources of PUFA, including oil and animal source foods, resulting in a low estimated mean total consumption of PUFA $(5 \cdot 1 \mathrm{~g} / \mathrm{d})$. Almost all women were estimated to consume less than the recommended intake levels for total fat, total PUFA, $\alpha$-linolenic acid (ALA) and DHA. Median breast-milk linoleic acid (8.5\% weight) and ALA (0.2\%) concentrations were among the lowest reported in the literature, in contrast with arachidonic acid (0.5\%) and DHA $(0.3 \%)$ concentrations, which were mid-range. Bangladeshi women in general, and especially those who practise prolonged breast-feeding, may benefit from increased consumption of food sources of PUFA.
\end{abstract}

Key words: Breast-feeding: PUFA: DHA: Arachidonic acid

To promote normal child growth, development and immune function, mothers must supply their children with adequate amounts of PUFA during pregnancy and lactation ${ }^{(1,2)}$. In particular, maternal fat stores and dietary intake must be adequate to allow for sufficient transfer of linoleic acid (LA), arachidonic acid (ARA), $\alpha$-linolenic acid (ALA), EPA and DHA to the child. In resource-poor countries, breast milk composition is especially important, as children often depend on breast milk as an important source of fat for as long as they continue to breast-feed ${ }^{(3,4)}$.

The 2008 Joint WHO/FAO Expert Consultation on Fats and Fatty Acids in Human Nutrition recommended that all women of reproductive age, including pregnant and lactating women, consume $20-35 \%$ of total energy as fat, with $6-11 \%$ of total energy from PUFA and at least 2 and $0.5 \%$ of total energy from LA and ALA, respectively ${ }^{(5,6)}$. Estimated minimum intakes of LA and ALA that will prevent essential fatty acid (EFA) deficiency are 1 and $0 \cdot 2 \%$ of total energy, respectively ${ }^{(7,8)}$. Both the WHO/FAO Expert Consultation and the Perinatal Lipid Intake Working Group specifically recommend that pregnant and lactating women consume a usual daily intake of $200 \mathrm{mg} \mathrm{DHA} / \mathrm{d}^{(5,9)}$.

Maternal fat stores are another source of PUFA for transfer to the child, and there is consensus that both

Abbreviations: ALA, $\alpha$-linolenic acid; ARA, arachidonic acid; EFA, essential fatty acid; FAME, fatty acid methyl ester; ICDDR,B, International Centre for Diarrhoeal Disease Research, Bangladesh; LA, linoleic acid; SES, socio-economic status.

*Corresponding author: E. A. Yakes, fax +1 530752 3406, email eyakes@ucdavis.edu 
adequate pre-pregnancy weight $\left(\mathrm{BMI} \geq 18.5 \mathrm{~kg} / \mathrm{m}^{2}\right.$ ) and appropriate gestational weight gain are important for maternal and child health ${ }^{(10,11)}$. Energy intake during lactation must adequately support milk production and prevent lean tissue loss and excessive depletion of adipose stores. During the first 6 months of lactation, the estimated additional energy needs for poorly nourished women are about $711.3 \mathrm{~kJ} / \mathrm{d}(170 \mathrm{kcal} / \mathrm{d})$ higher than those for well-nourished women $^{(12)}$. The energy requirements for lactation beyond 6 months differ depending on the amount of milk being produced $^{(12)}$.

The amount of PUFA delivered in human milk varies in different populations. Milk PUFA content is influenced by a number of factors, including maternal dietary intake, maternal fat stores, endogenous synthesis of fats and regulatory mechanisms affecting fatty acid transport and synthesis in the mammary gland ${ }^{(13-16)}$. Bangladeshi women of child-bearing age may have inadequate fat intake and fat stores. Dietary surveys of households and lactating women in Bangladesh have broadly characterised the rural Bangladeshi diet as being very low in fat and high in carbohydrates, but specific intakes of PUFA have not been examined ${ }^{(17,18)}$. Rural Bangladeshi women store very little fat during pregnancy and consistently lose weight during the first 2 years of lactation ${ }^{(17,19,20)}$. The median duration of breast-feeding in Bangladesh is 32.8 months, with $78 \%$ of children still receiving some breast milk at 24 months of age ${ }^{(21)}$.

The present study examined data from Bangladeshi mothers of children 24-48 months of age. Our aims were to examine the relationship between prolonged breast-feeding and maternal BMI, to compare the fat and energy intakes of breast-feeding and non-breast-feeding mothers, to assess the adequacy of fat intake in rural Bangladeshi mothers and to determine breast-milk fatty acid composition in a subsample of mothers. We also examined the relationships between maternal fat intake and several potentially associated factors, including season and maternal age, BMI, education level, socio-economic status (SES) and site of residence. These data are unique in that they characterise maternal dietary intake and breast-milk PUFA content during prolonged lactation; the vast majority of the work done previously on this topic has focused on the first 6 months of lactation. Based on the anthropometric status, dietary fat intake and prolonged lactation of these mothers, we hypothesised that the PUFA content of their breast milk would be lower than that observed for breast milk that was previously reported in the literature.

\section{Subjects and methods \\ Study design}

The study was designed as a cross-sectional, representative, multi-stage survey of mothers of children 24-48 months of age who resided in one of two rural districts of the northern poverty belt of Bangladesh. The present study was conducted according to the guidelines laid down in the Declaration of
Helsinki, and all procedures involving human subjects were approved by the Institutional Review Board of the University of California, Davis and the Ethical Review Committee (ERC) of the International Centre for Diarrhoeal Disease Research, Bangladesh (ICDDR,B). Written informed consent was obtained from all study participants.

\section{Study sites and selection of study participants}

We selected two rural 'upazilas', Trishal and Pirgacha, in northern Bangladesh, based on their high prevalence of poverty and food insecurity and the presence of some existing research infrastructure established by the ICDDR,B.

Within each 'upazila', all villages or 'mauzas' (administrative subdivisions) identified by the 2001 census were included in the sampling universe. There were a total of 159 clusters ('mauzas' or villages) in Trishal and 169 clusters in Pirgacha. During the first sampling stage, twenty-five clusters were selected from each study site using systematic sampling with the probability of selection proportional to estimated population size. At the second stage of sampling, ten households within each cluster were selected using a global positioning system sampling $\operatorname{method}^{(22)}$. The study sites and our sampling methods have been previously described in detail ${ }^{(23)}$.

Approximately $92 \%$ of the originally selected eligible households agreed to participate in the study. Data were collected from 240 households in Trishal from October 2007 to May 2008 and from 240 households in Pirgacha from January to June 2008. Forms for one household in Trishal were lost during transit from the field site to the ICDDR,B. The present analysis excluded data from households in which the primary carer was the father $(n 1)$ or a woman older than reproductive age (age $\geq 55$ years; $n$ 4). Thus, the total sample size was 474 women of reproductive age, $4 \%$ of whom were grandmothers of the study children.

\section{Data collection and processing}

Dietary data were collected by fieldworkers posted in recruited households for $12 \mathrm{~h}$ periods on two non-consecutive days during the course of a 1-week period. A fieldworker observed food preparation and consumption, and used a frequently standardised food scale $( \pm 1 \mathrm{~g}$, MyWeigh KD7000; MyWeigh, Phoenix, AZ, USA) to measure the weights of all foods included in recipes, the weights of recipes before and after cooking and the weights of foods and mixed preparations served and leftover after consumption. Animal source foods included in mixed preparations (e.g. fish in a vegetable curry) were weighed separately at the point of consumption to estimate actual intake. On the morning after the $12 \mathrm{~h}$ observation period, a fieldworker returned to the household to elicit information on any food consumed during the $12 \mathrm{~h}$ period after the previous day's observation ended. A standardised plate, cup and spoon were used to assist with portion size estimation, and fieldworkers reviewed all information with the carer after the initial list of foods was 
completed to probe for food items that may have been forgotten. Child's breast milk intake was estimated by the test-weighing procedure, which has been previously described in detail ${ }^{(23)}$.

Foods consumed were converted to nutrients using the USDA Nutrient Database for Standard Reference (Release $20)^{(24)}$ and the International Minilist ${ }^{(25)}$. Food sources of nutrients were calculated by summing the total nutrient intakes for all observation days, summing the nutrient intakes from each food source and calculating the percentage of total nutrient intake from each food.

A trained field-worker measured maternal height using a portable stadiometer $( \pm 0 \cdot 1 \mathrm{~cm}$, ShorrBoard; Shorr Productions, Olney, MD, USA) and maternal weight using a frequently standardised electronic scale $( \pm 100 \mathrm{~g}$, Seca 840 Digital Floor Scale; Seca, Hamburg, Germany). If two height measurements differed by more than $0.5 \mathrm{~cm}$, a third height measurement was taken. Average weight and the average of the two closest height values were used to calculate BMI $\left(\mathrm{kg} / \mathrm{m}^{2}\right)$.

Information on SES and agricultural practices was gathered during interviews with the carer and the head of the household.

Biological samples were collected from six enrolled households in a cluster. Breast milk was collected from lactating mothers starting in December 2007 (2 months after the start of the study) due to a delay in obtaining Ethical Review Committee approval. Of the 474 carers of reproductive age enrolled in the study, 242 were breast-feeding a child between 24 and 48 months of age and 128 of these women were from households who participated in biological sample collection in the period after breast milk collection started. These women were asked to provide a breast milk sample, and ninety-eight (77\%) gave a sample. Reasons for not providing a sample included refusal and difficulties with producing a milk sample via hand expression.

Efforts were made to standardise both the time of day and the time elapsed since the last feeding for breast milk collection $^{(26)}$. Carers were brought to a central collection site (health complex or school) early in the morning and were asked to breast-feed their children upon arrival and then again 60 min later. During this latter feed, a female fieldworker assisted the mother with hand expressing approximately $3.5 \mathrm{ml}$ of human milk into a sterile conical vial from the last breast suckled during the previous feed. Breast milk samples were transported to the field laboratory on crushed ice and then gently inverted several times and aliquoted to storage vials. The breast milk aliquots were stored in a freezer $\left(-20^{\circ} \mathrm{C}\right)$ with a back-up generator for 1 week to 6 months (depending on the date of collection) until being shipped to ICDDR,B and then to University of California, Davis on dry ice. At the ICDDR,B and University of California, Davis, the samples were stored at $-80^{\circ} \mathrm{C}$ until extraction and derivatisation.

A sample of $30 \mu \mathrm{l}$ (approximately $0.03 \mathrm{~g}$ ) human milk was used for fatty acid methyl ester (FAME) analysis. Both the human milk and an authentic internal standard (TAG (17:0); Avanti Polar Lipids, Alabaster, AL, USA) were measured by weight, and then the Folch method was used for lipid extraction ${ }^{(27)}$. The organic phase was then evaporated under $\mathrm{N}_{2}$. The dried organic extracts were methylated by adding $1 \mathrm{ml}$ of $3 \mathrm{M}$-methanolic $\mathrm{HCl}$ and incubating in a sealed vial for $12 \mathrm{~h}$ at $60^{\circ} \mathrm{C}$. FAME were extracted in hexane with $0.01 \%$ butylated hydroxytoluene after neutralisation of the methanolic hydrochloric acid with 5\% potassium bicarbonate. FAME extracts were dried under vacuum and then dissolved in hexane for analysis by GC.

FAME were separated via capillary GC using an Agilent Technologies (Santa Clara, CA, USA) gas chromatograph model 7890 equipped with a $30 \mathrm{~m}$ DB225MS capillary column (J\&W Scientific, Folsom, CA, USA) and a flame ionisation detector. An authentic GLC reference standard (461; Nu-Chek Prep, Elysian, MN, USA) and Agilent Technologies GC ChemStation software were used to identify and quantify the FAME peaks. Every chromatogram was reviewed to check for proper peak integration and identification. Percentage of fatty acids by weight was calculated by dividing the peak area for a particular fatty acid by the total sum of the peak areas for all identified fatty acids.

\section{Data analysis}

We used the National Cancer Institute method for episodically consumed foods to estimate distributions of usual food and nutrient intake ${ }^{(28,29)}$. This method was used to better approximate the variance of the intake distributions by removing within-person variation and to improve estimates of intake for foods and nutrients that were episodically consumed during the $2 \mathrm{~d}$ of dietary data collection. Briefly, the National Cancer Institute method uses data from two or more $24 \mathrm{~h}$ estimates of intake in a two-part model that first estimates the probability of consumption using logistic regression and then estimates the amount consumed using linear mixed regression on a transformed scale $\mathrm{e}^{(28)}$

The covariates of interest for both the probability of consumption and the amount of consumption models included maternal age, BMI, education level, household access to electricity and housing quality (as proxies of household wealth), season and site of residence. The housing quality variable was a composite continuous measure assessing the type of floors, walls and sanitary facilities in the family home, and the type of cooking fuel used. Maternal education was a continuous variable that was categorised to minimise the effects of measurement error. All other continuous variables (maternal age, BMI and house quality score) were used as continuous variables in the models. The first model (probability of consumption) was of the form ${ }^{(28)}$ :

Logit(24h intake probability)

$$
\begin{aligned}
& =\text { intercept }_{1}+\beta 1_{\text {age }} \times \text { age }+\beta_{1 \mathrm{BMI}} \times \mathrm{BMI}+\beta_{1 \text { educ }} \times \text { educ } \\
& +\beta_{1 \text { elec }} \times \text { elec }+\beta_{1 \text { house }} \times \text { house }+\beta_{1 \text { season }} \times \text { season } \\
& +\beta_{1 \text { site }} \times \text { site }+ \text { person-specific effect }{ }_{1} .
\end{aligned}
$$


The second model (amount of consumption) was of the form ${ }^{(28)}$ :

Transformed $24 \mathrm{~h}$ intake estimate

$$
\begin{aligned}
& =\text { intercept } 2+\beta_{2 \text { age }} \times \text { age }+\beta_{2 \mathrm{BMI}} \times \mathrm{BMI}+\beta_{2 \text { educ }} \times \text { educ } \\
& +\beta_{2 \text { elec }} \times \text { elec }+\beta_{2 \text { house }} \times \text { house }+\beta_{2 \text { season }} \times \text { season } \\
& +\beta_{2 \text { site }} \times \text { site }+ \text { person-specific effect } 2 \\
& + \text { within-person variability } \\
& + \text { random error of the regression. }
\end{aligned}
$$

Both models were used to estimate distributions of intake for foods and nutrients that were episodically consumed, including oil, eggs, fish, meat/poultry, ARA, EPA and DHA. Only the amount of consumption model was used for all other foods and nutrients because they were consumed in some amount by all participants on all observation days. The percentage of energy derived from fat, carbohydrate and protein was calculated for each woman on each day; these distributions estimate the long-term mean of the daily ratio of intakes (the usual ratio of intakes) ${ }^{(30)}$. Distributions of intakes were estimated for the entire maternal population who had complete covariate information $(n$ 455) and for the breast-feeding and non-breast-feeding subgroups. Covariates were assessed as being significantly associated with intake based on test statistics from the fitted models.

The SURVEYLOGISTIC procedure in SAS (version 9.2; SAS, Cary, NC, USA) was used to analyse the relationships between maternal characteristics and breast-feeding status, and the SURVEYREG procedure was used to analyse the relationships between maternal characteristics and total milk fat content. These procedures allow for correct estimation of standard errors and test statistics in survey samples.

\section{Results}

\section{Characteristics of women and study households}

Table 1 presents the characteristics of Bangladeshi mothers included in the study sample and their households. The women ranged in age from 16 to 50 (median 25) years, and their BMI ranged from 14.5 to 36.7 (median 19.1) $\mathrm{kg} / \mathrm{m}^{2}$. Maternal weight ranged from 30.0 to 82.0 (median 43.1 ) kg, and height ranged from 131.8 to 168.6 (median $150 \cdot 2$ ) cm. Approximately, $40 \%$ of the mothers had not completed any formal education, and $70 \%$ did not have access to electricity. A small number of households ( $8 \%$ ) were surveyed before the major rice harvest (pre-Aman harvest; October-November); the remaining households were surveyed after the main harvest (50\%; post-Aman harvest; December-March) and during the secondary rice harvest ( $42 \%$; Aus/Boro harvest; April-June). A total of 274 women ( $58 \%$ of total female carers of reproductive age) were currently breast-feeding, with 241 women breast-feeding a 24-48-month-old child and the rest ( $n$ 33) breast-feeding a younger sibling. About
$76 \%$ of $24-35$-month-old children and $38 \%$ of $36-48$ month-old children nursed an average of $\geq 5$ times/d on the observation days.

\section{Relationships between breast-feeding status and covariates of interest}

Bivariate relationships between breast-feeding status and the covariates of interest were examined (Table 1), and breastfeeding status was not significantly associated with access to electricity, housing quality, maternal age, maternal education level, season of data collection or district of residence. Maternal BMI, however, was significantly associated with lactation status. Approximately $42 \%$ of breast-feeding mothers were underweight $\left(\mathrm{BMI}<18.5 \mathrm{~kg} / \mathrm{m}^{2}\right.$ ) compared with $26 \%$ of non-breast-feeding mothers $(P=0.0003)$. The significant relationship between breast-feeding status and maternal BMI persisted in a multivariate model that adjusted for access to electricity, housing quality, maternal education, maternal age and season. On average, mothers who were breast-feeding had a BMI $0.8 \mathrm{~kg} / \mathrm{m}^{2}$ less than non-breast-feeding mothers ( $P=0 \cdot 001)$.

\section{Energy intake and macronutrient profile of diet}

Table 2 shows estimated distributions of usual energy, macronutrient and EFA intake, expressed as a percentage of total energy. The mean (5th-95th percentile) daily energy intake for all women was $7870(6782-8979) \mathrm{kJ} / \mathrm{d}$. Almost all of the women in the study population consumed more than $75 \%$ of their total energy from carbohydrates. Intakes from protein had a relatively narrow range, with most women consuming about $10 \%$ of their energy from protein. The maternal diet averaged $7 \cdot 8 \%$ of total energy from fat and 2 and $0.33 \%$ of total energy from LA and ALA, respectively.

After adjusting for maternal age, BMI, education level, SES and site of residence in separate linear mixed regression models, intakes of total energy, carbohydrates and protein as a percentage of total energy did not differ by lactation status. Intakes of total fat $(\beta=-0.07 ; P=0 \cdot 04)$, LA $(\beta=-0 \cdot 10$; $P=0.03)$ and ALA $(\beta=-0 \cdot 12 ; P=0 \cdot 01)$, expressed as a percentage of total energy, were slightly lower in breast-feeding than in non-breast-feeding women in the same model. SES was significantly associated with higher intakes of protein (electricity access: $\beta=0.03 ; P=0.01$; better housing quality: $\beta=0.03 ; P=0.002$ ) and fat (better housing quality: $\beta=0.20$; $P<0.0001$; maternal access to formal education: $\beta=0 \cdot 11$; $P=0.003$ ) and lower intakes of carbohydrates (better housing quality: $\beta=-1.7 ; P=0.02)$ as a percentage of total energy in separate linear mixed regression models.

Based on the intake distributions, it is estimated that $99 \%$ of the women in the study sample had usual fat intakes less than $20 \%$ of total energy, and $84 \%$ had usual fat intakes of less than $10 \%$ of total energy. Almost all women (99\%) were estimated to consume less than $6 \%$ of total energy from PUFA. About $60 \%$ of women consumed less than $2 \%$ of total energy from LA, and $90 \%$ consumed less than $0.5 \%$ of total energy from ALA. An estimated 7 and $13 \%$ of mothers had a usual intake 
Table 1. Characteristics of rural Bangladeshi mothers included in the study and their households, by the women's current breastfeeding status

(Numbers of subjects and percentages)

\begin{tabular}{|c|c|c|c|c|c|c|c|}
\hline & \multicolumn{2}{|c|}{$\begin{array}{l}\text { All mothers } \\
\left(\begin{array}{l}n \text { 474) }\end{array}\right.\end{array}$} & \multicolumn{2}{|c|}{$\begin{array}{l}\text { Non-breast- } \\
\text { feeding mothers } \\
(n 200)\end{array}$} & \multicolumn{2}{|c|}{$\begin{array}{l}\text { Breast-feeding } \\
\text { mothers } \\
(n 274)\end{array}$} & \multirow[b]{2}{*}{$P^{*}$} \\
\hline & $n$ & $\%$ & $n$ & $\%$ & $n$ & $\%$ & \\
\hline \multicolumn{8}{|l|}{ Maternal age (years) } \\
\hline $16-25$ & 258 & 54 & 103 & 51 & 155 & 56 & 0.21 \\
\hline $26-35$ & 157 & 33 & 67 & 34 & 90 & 33 & \\
\hline$\geq 36$ & 59 & 12 & 30 & 15 & 29 & 11 & \\
\hline \multicolumn{8}{|l|}{ Maternal BMI† $\left(\mathrm{kg} / \mathrm{m}^{2}\right)$} \\
\hline Grade 3 CED $(\mathrm{BMI}<16)$ & 18 & 4 & 9 & 4 & 9 & 3 & $<0.0001$ \\
\hline Grade 2 CED (BMI 16-16.99) & 34 & 7 & 9 & 4 & 25 & 9 & \\
\hline Grade 1 CED (BMI 17-18.49) & 117 & 25 & 35 & 18 & 82 & 30 & \\
\hline Normal (BMI 18.5-22.99) & 247 & 52 & $115 \ddagger$ & 58 & 132 & 48 & \\
\hline $\begin{array}{l}\text { At-risk for overweight } \\
\text { (BMI 23-24.99) }\end{array}$ & 25 & 5 & 17 & 8 & 8 & 3 & \\
\hline Overweight (BMI $\geq 25$ ) & 20 & 4 & 10 & 5 & 10 & 4 & \\
\hline Missing data & 13 & 3 & 5 & 2 & 8 & 3 & \\
\hline \multicolumn{8}{|l|}{ Maternal height $(\mathrm{cm})$} \\
\hline Stunted $(<145)$ & 82 & 17 & 33 & 17 & 51 & 19 & 0.68 \\
\hline Non-stunted ( $\geq 145)$ & 379 & 80 & 162 & 81 & 215 & 78 & \\
\hline Missing data & 13 & 3 & 5 & 3 & 8 & 3 & \\
\hline \multicolumn{8}{|l|}{ Maternal weight (kg) } \\
\hline$<40$ & 136 & 29 & 43 & 21 & 43 & 16 & $<0.007$ \\
\hline$\geq 40-<50$ & 239 & 50 & 109 & 55 & 130 & 47 & \\
\hline$\geq 50$ & 86 & 18 & 43 & 21 & 93 & 34 & \\
\hline Missing data & 13 & 3 & 5 & 3 & 8 & 3 & \\
\hline \multicolumn{8}{|c|}{ Maternal completion of any formal education } \\
\hline No & 186 & 39 & 86 & 43 & 100 & 36 & 0.20 \\
\hline Yes & 282 & 59 & 113 & 56 & 169 & 62 & \\
\hline Missing data & 6 & 2 & 1 & 1 & 5 & 2 & \\
\hline \multicolumn{8}{|l|}{ Electricity access } \\
\hline No & 332 & 70 & 136 & 68 & 196 & 72 & 0.40 \\
\hline Yes & 135 & 28 & 63 & 31 & 72 & 26 & \\
\hline Missing data & 7 & 2 & 1 & 1 & 6 & 2 & \\
\hline \multicolumn{8}{|l|}{ Housing quality } \\
\hline Low score $(<2)$ & 164 & 35 & 67 & 34 & 97 & 35 & 0.87 \\
\hline Middle score $(2-3)$ & 263 & 55 & 114 & 57 & 149 & 54 & \\
\hline High score $(>3)$ & 36 & 8 & 16 & 8 & 20 & 7 & \\
\hline Missing data & 11 & 2 & 3 & 2 & 8 & 3 & \\
\hline \multicolumn{8}{|l|}{ Site of residence } \\
\hline Pirgacha & 239 & 50 & 107 & 54 & 132 & 48 & 0.29 \\
\hline Trishal & 235 & 50 & 93 & 46 & 142 & 52 & \\
\hline
\end{tabular}

CED, chronic energy deficiency.

* The $P$ value for the effect in a logistic regression model, with characteristic as the independent variable and maternal breast-feeding status (yes/no) as the outcome.

†BMI categories defined according to Shafique et al. ${ }^{(31)}$ and WHO Expert Consultation ${ }^{(54)}$

$\ddagger$ Three women in this category were pregnant. One was 3 months pregnant $\left(\mathrm{BMI}=22 \mathrm{~kg} / \mathrm{m}^{2}\right)$, one was 7 months pregnant $\left(\mathrm{BMl}=21 \mathrm{~kg} / \mathrm{m}^{2}\right)$ and one was 9 months pregnant $\left(\mathrm{BMI}=19 \mathrm{~kg} / \mathrm{m}^{2}\right)$.

of LA and ALA less than 1 and $0 \cdot 2 \%$ of total energy, respectively, placing them at a potential risk of EFA deficiency.

\section{Maternal consumption of fatty acids}

Table 3 presents the women's estimated distributions of usual fat intake expressed as $\mathrm{g} / \mathrm{d}$. The mean intake of total fat for all women was $16.3 \mathrm{~g} / \mathrm{d}$. The average ratio of LA:ALA intake in the maternal diet was $6 \cdot 7$, with a 5 th-95th percentile range of 4.4-9.7. After adjusting for maternal age, BMI, education level, SES and site of residence in a linear mixed regression model, breast-feeding status was not a significant predictor of total fat intake or intake of any of the fat subclasses. Total fat intake was significantly associated with several other fac- tors in the model, including season (lowest in the pre-Aman harvest: $\beta=-0.08 ; \quad P=0.04)$, maternal age $(\beta=-0.01$; $P=0.02)$, maternal BMI $(\beta=0.02 ; P=0.02)$, housing quality ( $\beta=0.22 ; P=<0.0001)$, maternal level of formal education $(\beta=0.11 ; P=0.02)$ and site of residence (lower in Trishal: $\beta=-0 \cdot 16 ; P=0 \cdot 001)$. Similar associations were observed for intake of the fat subclasses.

\section{Food sources of fatty acids in the maternal diet}

Vegetable oil was the source of about $50 \%$ of total fat intake for the entire carer population. Rice was also a prominent source of fat, providing $27 \%$ of the total fat in the maternal diet. Animal source foods, including freshwater fish, eggs, 
Table 2. Estimated distributions of usual energy intake and percentage of energy derived from fat, carbohydrate and protein among rural Bangladeshi women, by current breast-feeding status*

(Mean values and 5th-95th percentiles)

\begin{tabular}{|c|c|c|c|c|c|c|c|}
\hline & \multicolumn{2}{|c|}{ All women ( $n$ 455) } & \multicolumn{2}{|c|}{$\begin{array}{l}\text { Non-breast-feeding } \\
\text { women }(n \text { 196) }\end{array}$} & \multicolumn{2}{|c|}{$\begin{array}{l}\text { Breast-feeding } \\
\text { women }(n 259)\end{array}$} & \multirow[b]{2}{*}{$P \dagger$} \\
\hline & Mean & $\begin{array}{l}\text { 5th-95th } \\
\text { Percentiles }\end{array}$ & Mean & $\begin{array}{l}\text { 5th-95th } \\
\text { Percentiles }\end{array}$ & Mean & $\begin{array}{l}\text { 5th-95th } \\
\text { Percentiles }\end{array}$ & \\
\hline \multicolumn{8}{|l|}{ Energy } \\
\hline $\mathrm{kJ} / \mathrm{d}$ & 7870 & $6782-8979$ & 7778 & $6581-8908$ & 7941 & $6958-9029$ & 0.24 \\
\hline $\mathrm{kJ} / \mathrm{d}$ per $\mathrm{kg}$ & 179.9 & $121 \cdot 3-242 \cdot 7$ & $172 \cdot 8$ & $115.5-233.5$ & 185.4 & $106 \cdot 3-246 \cdot 9$ & 0.08 \\
\hline \multicolumn{8}{|l|}{ Total energy (\%) } \\
\hline Carbohydrate & $82 \cdot 0$ & $77 \cdot 2-86 \cdot 8$ & $81 \cdot 6$ & $76 \cdot 7-86 \cdot 3$ & $82 \cdot 3$ & $77 \cdot 6-87 \cdot 1$ & 0.12 \\
\hline Protein & $10 \cdot 1$ & $9 \cdot 2-11 \cdot 1$ & $10 \cdot 2$ & $9 \cdot 3-11 \cdot 1$ & $10 \cdot 1$ & $9.2-11 \cdot 0$ & 0.18 \\
\hline Fat & $7 \cdot 8$ & $4 \cdot 6-12 \cdot 3$ & 8.2 & $4 \cdot 9-12 \cdot 8$ & $7 \cdot 6$ & $4 \cdot 4-11 \cdot 8$ & 0.04 \\
\hline LA & $2 \cdot 0$ & $0.9-3.7$ & $2 \cdot \overline{2}$ & $1.0-3.9$ & 1.9 & $0.9-3.5$ & 0.03 \\
\hline ALA & 0.33 & $0.17-0.57$ & 0.35 & $0.18-0.61$ & 0.31 & $0.16-0.54$ & 0.01 \\
\hline
\end{tabular}

LA, linoleic acid; ALA, $\alpha$-linolenic acid.

* Percentage of energy derived from fat, carbohydrate and protein was calculated for each woman on each day; these distributions estimate the long-term mean of the daily ratio of intakes (the usual ratio of intakes) ${ }^{(30)}$

† Reported $P$-values are for the effects of lactation status on intake after adjusting for maternal age, BMI, education, socio-economic status and site of residence in a linear mixed regression model.

meat/poultry and dairy products, provided about $15 \%$ of total maternal fat intake. These patterns did not differ for breastfeeding and non-breast-feeding women.

The dietary patterns for PUFA were similar to those for total fat, with vegetable oil accounting for $57 \%$ of total PUFA intake and rice providing another 26\%. Vegetables and beans supplied about $6 \%$ of the total PUFA. Oil, rice, beans and vegetables (particularly leafy vegetables) were the most important sources of both LA and ALA. The primary food sources of ARA included freshwater fish (49\%), eggs (42\%) and meat/poultry (7\%). Almost all of the EPA and DHA were provided by freshwater fish. Again, the pattern of food intake was similar in breast-feeding and non-breast-feeding women.

Estimated usual intake distributions for food sources of PUFA $(\mathrm{g} / \mathrm{d})$ are shown in Table 4. There were significant differences in the probability of consumption of food sources of PUFA between the two study sites in a linear mixed model that adjusted for lactation status, maternal age, BMI, education level and SES. The probabilities of consuming soyabean oil $(\beta=4.0 ; P<0 \cdot 0001)$, meat/poultry $(\beta=0.87 ; P=0.002)$ and eggs $(\beta=1.2 ; P<0 \cdot 0001)$ were higher in Pirgacha, whereas the probabilities of consuming mustard oil $(\beta=2 \cdot 1$; $P<0.0001)$ and fish $(\beta=1.2 ; P<0.0001)$ were higher in Trishal.

\section{Breast-milk fatty acid composition}

The characteristics of mothers who provided a breast milk sample and their households were similar to those of the overall maternal population. The mean BMI for breast-feeding women who provided a sample was $18.8 \mathrm{~kg} / \mathrm{m}^{2}$, while the mean BMI for breast-feeding women who did not provide a sample because of lack of opportunity ( $n$ 114) or refusal/ difficulty with producing a sample from hand expression ( $n 30)$ was $19 \cdot 6 \mathrm{~kg} / \mathrm{m}^{2}(P=0 \cdot 01)$.

Table 5 lists the fatty acid content (\% wt) of the breast milk samples. The median total fat content for the samples was $3.5 \mathrm{~g} / 100 \mathrm{~g}$ of breast milk ( 5 th-95th percentile range,

Table 3. Estimated distributions of usual fat intake $(\mathrm{g} / \mathrm{d})$ by rural Bangladeshi women, by current breast-feeding status (Mean values and 5th-95th percentiles)

\begin{tabular}{|c|c|c|c|c|c|c|c|}
\hline \multirow[b]{2}{*}{ Type of fat } & \multicolumn{2}{|c|}{ All women $(n 455)$} & \multicolumn{2}{|c|}{$\begin{array}{l}\text { Non-breast-feeding } \\
\text { women }(n 196)\end{array}$} & \multicolumn{2}{|c|}{$\begin{array}{l}\text { Breast-feeding } \\
\text { women }(n 259)\end{array}$} & \multirow[b]{2}{*}{$P^{*}$} \\
\hline & Mean & $\begin{array}{l}\text { 5th-95th } \\
\text { Percentiles }\end{array}$ & Mean & $\begin{array}{l}\text { 5th-95th } \\
\text { Percentiles }\end{array}$ & Mean & $\begin{array}{l}\text { 5th-95th } \\
\text { Percentiles }\end{array}$ & \\
\hline Total fat & $16 \cdot 3$ & $8 \cdot 3-27 \cdot 9$ & $16 \cdot 9$ & $8 \cdot 6-28 \cdot 8$ & $15 \cdot 9$ & $8 \cdot 1-27 \cdot 1$ & 0.48 \\
\hline Saturated fat & 3.4 & $1 \cdot 8-5 \cdot 8$ & 3.6 & $1 \cdot 9-6 \cdot 1$ & $3 \cdot 3$ & $1 \cdot 7-5 \cdot 6$ & 0.34 \\
\hline MUFA & $5 \cdot 6$ & $2 \cdot 8-9 \cdot 7$ & $5 \cdot 7$ & $2 \cdot 8-9 \cdot 8$ & $5 \cdot 6$ & $2 \cdot 8-9 \cdot 7$ & 0.93 \\
\hline PUFA & $5 \cdot 1$ & $2 \cdot 1-9.9$ & 5.4 & $2 \cdot 2-10 \cdot 4$ & 4.9 & $2 \cdot 0-9 \cdot 5$ & 0.24 \\
\hline LA & $4 \cdot 3$ & $1 \cdot 7-8.5$ & 4.5 & $1 \cdot 8-8.9$ & $4 \cdot 1$ & $1 \cdot 6-8 \cdot 1$ & 0.28 \\
\hline ARA & 0.04 & $0.01-0.08$ & 0.04 & $0.01-0.08$ & 0.03 & $0.01-0.07$ & 0.99 \\
\hline ALA & 0.7 & $0.3-1 \cdot 2$ & 0.7 & $0.3-1 \cdot 3$ & 0.7 & $0 \cdot 3-1 \cdot 2$ & 0.11 \\
\hline EPA & 0.03 & $0.01-0.07$ & 0.03 & $0.01-0.07$ & 0.03 & $0.01-0.07$ & 0.91 \\
\hline DHA & 0.03 & $0.01-0.06$ & 0.03 & $0.01-0.06$ & 0.03 & $0.01-0.05$ & 0.72 \\
\hline
\end{tabular}

LA, linoleic acid; ARA, arachidonic acid; ALA, $\alpha$-linolenic acid.

${ }^{*}$ Reported $P$-values are for the effects of lactation status on intake after adjusting for maternal age, BMI, education, socio-economic status and site of residence in a linear mixed regression model. 
Table 4. Estimated usual consumption ( $\mathrm{g} / \mathrm{d}$ ) of food sources of PUFA by rural Bangladeshi women, by current breast-feeding status (Mean values and 5 th-95th percentiles)

\begin{tabular}{|c|c|c|c|c|c|c|c|}
\hline \multirow[b]{2}{*}{ Food source } & \multicolumn{2}{|c|}{ All women ( $n$ 455) } & \multicolumn{2}{|c|}{$\begin{array}{l}\text { Non-breast-feeding } \\
\text { women }(n 196)\end{array}$} & \multicolumn{2}{|c|}{$\begin{array}{l}\text { Breast-feeding } \\
\text { women (n 259) }\end{array}$} & \multirow[b]{2}{*}{$P^{*}$} \\
\hline & Mean & $\begin{array}{l}\text { 5th-95th } \\
\text { Percentiles }\end{array}$ & Mean & $\begin{array}{l}\text { 5th-95th } \\
\text { Percentiles }\end{array}$ & Mean & $\begin{array}{l}\text { 5th-95th } \\
\text { Percentiles }\end{array}$ & \\
\hline Fish & $12 \cdot 8$ & $2 \cdot 1-34 \cdot 2$ & $13 \cdot 3$ & $2 \cdot 1-36 \cdot 9$ & $12 \cdot 3$ & $2 \cdot 1-32 \cdot 5$ & 0.99 \\
\hline Eggs & $4 \cdot 7$ & $0.8-11.6$ & $4 \cdot 6$ & $0.8-11.5$ & $4 \cdot 7$ & $0.8-11.7$ & 0.40 \\
\hline Meat/poultry & $4 \cdot 2$ & $0.5-12.8$ & $5 \cdot 0$ & $0.6-14.8$ & $3 \cdot 6$ & $0.4-11.0$ & 0.83 \\
\hline Mustard oil & $4 \cdot 0$ & $0.3-10.4$ & $3 \cdot 5$ & $0 \cdot 2-9 \cdot 2$ & $4 \cdot 3$ & $0.3-11.0$ & 0.09 \\
\hline Soyabean oil & 3.5 & $0-11.9$ & $4 \cdot 3$ & $0-13 \cdot 0$ & $3 \cdot 0$ & $0-10.9$ & $0 \cdot 16$ \\
\hline
\end{tabular}

$1 \cdot 4-7 \cdot 3)$. Total milk fat content was not significantly associated with maternal BMI $(P=0 \cdot 22)$ or with breast-feeding frequency $(P=0 \cdot 42)$ or duration $(P=0 \cdot 18)$. The majority of the fatty acids present in the human milk were SFA, followed by MUFA and then PUFA. The most abundant fatty acids were $16: 0,18: 1$, $14: 0$ and $18: 2 n-6$ (LA). The median ratio of LA:ALA in the milk was 35 , while the median ratio of long-chain $n$-6:long chain $n-3$ fatty acids was $1 \cdot 6$. Breast-milk ARA and DHA concentrations were highly correlated $(r 0 \cdot 7 ; P<0 \cdot 001)$.

\section{Discussion}

Our data support the concerns raised by earlier studies regarding the adequacy of fat stores in lactating Bangladeshi women. Overall, the BMI patterns for the women in the present study were similar to those observed in the nationally representative 2000-4 Nutritional Surveillance Project ${ }^{(31)}$. However, we found that women who were breast-feeding a 24-48-monthold child had a considerably higher prevalence of underweight (BMI $<18.5 \mathrm{~kg} / \mathrm{m}^{2}$ ) than non-breast-feeding women with a 24-48-month-old child.

As our data are cross-sectional, we cannot determine the postpartum period during which the weight discrepancy between these groups was established, or definitively establish that the energy demands of lactation were the cause of this weight discrepancy. Longitudinal studies in both wellnourished American women and poorly nourished Bangladeshi women found that breast-feeding women experienced the most weight loss from 3 to 6 months postpartum ${ }^{(17,32)}$. For the American mothers, the weight differences that were observed between breast-feeding and formula-feeding mothers were no longer significant after 12 months, indicating that the breast-feeding mothers probably experienced some weight recovery as breast-feeding intensity decreased ${ }^{(32)}$. The Bangladeshi mothers in the longitudinal study were not followed past 13 months postpartum. A cross-sectional study of rural Bangladeshi women in the Jhenaidah district found that the weights of lactating women were lower than those of non-lactating women throughout 48 months of lactation after controlling for height, education and food consumption; however, the differences were only significant up to 24 months postpartum $^{(20)}$. Milk production was not quantified in that study, but the authors hypothesised that decreased milk production after 24 months may have allowed maternal weight to recover ${ }^{(20)}$.
There was no significant difference in energy intake between lactating and non-lactating women after adjusting for maternal age, BMI, education level, SES and site of residence. Based on estimated mean $24 \mathrm{~h}$ breast milk consumption for the children in the present study (145 g/d for 24-35month-old children; $90 \mathrm{~g} / \mathrm{d}$ for 36-48-month-old children) and assuming that maternal fat stores were not covering additional energy needs, the breast-feeding women in the

Table 5. Fatty acid composition of breast milk from rural Bangladeshi mothers

(Median values and 5th-95th percentiles, $n$ 98)

\begin{tabular}{|c|c|c|}
\hline \multirow[b]{2}{*}{ Fatty acids } & \multicolumn{2}{|c|}{ Total fatty acids by wt (\%) } \\
\hline & Median & 5th-95th Percentiles \\
\hline \multicolumn{3}{|l|}{ SFA } \\
\hline $14: 0$ & $14 \cdot 2$ & $9 \cdot 1-21 \cdot 9$ \\
\hline $15: 0$ & 0.3 & $0.1-0.5$ \\
\hline $16: 0$ & $25 \cdot 2$ & $18 \cdot 8-32 \cdot 5$ \\
\hline $18: 0$ & 3.6 & $2 \cdot 6-5 \cdot 1$ \\
\hline $20: 0$ & 0.1 & $0.1-0.2$ \\
\hline $22: 0$ & 0.2 & $0.1-0.3$ \\
\hline $24: 0$ & 0.0 & $0.0-0.1$ \\
\hline Total SFA & 44.5 & $31.5-55.0$ \\
\hline \multicolumn{3}{|l|}{ MUFA } \\
\hline $14: 1$ & 0.2 & $0.1-0.3$ \\
\hline $16: 1 n-7$ & $3 \cdot 2$ & $1.4-5.6$ \\
\hline $18: 1$ & $21 \cdot 1$ & $13 \cdot 1-28 \cdot 4$ \\
\hline $20: 1$ & 0.4 & $0.2-1.1$ \\
\hline $22: 1$ & 0.3 & $0.0-1.5$ \\
\hline $24: 1$ & 0.2 & $0.1-0.4$ \\
\hline Total MUFA & $25 \cdot 6$ & $16 \cdot 6-33.9$ \\
\hline \multicolumn{3}{|l|}{ PUFA } \\
\hline $18: 2 n-6$ & 8.5 & $5 \cdot 0-13 \cdot 3$ \\
\hline $18: 3 n-6$ & 0.9 & $9 \cdot 4-2 \cdot 3$ \\
\hline $20: 3 n-6$ & 0.3 & $0.2-0.5$ \\
\hline $20: 4 n-6$ & 0.5 & $0.3-0.7$ \\
\hline $22: 4 n-6$ & $0 \cdot 1$ & $0.1-0.2$ \\
\hline Total $n-6$ & $10 \cdot 4$ & $6 \cdot 4-16 \cdot 7$ \\
\hline $18: 3 n-3$ & 0.2 & $0.1-0.4$ \\
\hline $20: 3 n-3$ & 0.0 & $0.0-0.1$ \\
\hline $20: 5 n-3$ & 0.1 & $0.0-0.1$ \\
\hline $22: 5 n-3$ & $0 \cdot 1$ & $0.1-0.2$ \\
\hline $22: 6 n-3$ & 0.3 & $0.2-0.5$ \\
\hline Total $n-3$ & 0.8 & $0.5-1.3$ \\
\hline Total PUFA & $11 \cdot 2$ & $6 \cdot 9-17 \cdot 8$ \\
\hline PUFA:SFA ratio & 0.2 & $0.1-0.5$ \\
\hline LA:ALA ratio & $35 \cdot 2$ & $24 \cdot 2-141 \cdot 9$ \\
\hline LC $n-6:$ LC $n-3$ ratio & 1.6 & $1.0-2.4$ \\
\hline
\end{tabular}

LA, linoleic acid; ALA, $\alpha$-linolenic acid; LC, long-chain. 
present study needed about $301-502 \mathrm{~kJ} / \mathrm{d}$ in excess to support milk production (range of maternal energy needs based on 1st and 99th percentiles of the child's breast milk intake: $29-1799 \mathrm{~kJ} / \mathrm{d}$ in excess $)^{(12,33)}$. We may not have had the power to detect a difference in intake of $418 \mathrm{~kJ}$ between the two groups; a post hoc power analysis showed that the power to detect this difference in the present study is $48 \%$. It is also possible that we may have underestimated energy intake, although this would not affect our ability to find a difference in energy intake between the two groups unless it was differential between breast-feeding and non-breastfeeding women. The women in the present study spent most of the day engaged in household activities (cooking, cleaning, child care and grain processing). Bangladeshi women with similar activity profiles were found to have physical activity levels of 1.59 (lightly active) in a study that used the doubly labelled water method ${ }^{(34)}$ and 1.76 (moderately active) in a study that used the $\mathrm{FAO} / \mathrm{WHO} / \mathrm{UNU}$ factorial method $^{(25)}$. Based on these physical activity levels, the total estimated energy expenditures for a woman weighing $43 \mathrm{~kg}$ with an estimated BMR of $4700 \mathrm{~kJ} / \mathrm{d}$ would be 7473 and $8272 \mathrm{~kJ}$, respectively ${ }^{(12)}$. These total estimated energy expenditures correspond to approximately the 25 th and 75 th percentiles of estimated energy intake for both lactating and non-lactating women in the present study.

Our data also support the concerns raised by earlier studies regarding the adequacy of fat intake in Bangladeshi women $^{(17,18)}$. We found that women in rural Bangladesh consumed a very low-fat, high-carbohydrate diet, with an estimated average of just $7 \cdot 8 \%$ total energy from fat. Intakes of fat were similar among breast-feeding and non-breast-feeding women. The main sources of fat in the diet were fairly limited, with vegetable oil and rice contributing the most to overall fat intake. There were significant geographical differences in the consumption of the animal source foods that are good sources of long-chain PUFA. These differences are probably due to the differences in availability and local preference and have important implications for programme planning. Based on distributions of usual food intake, Bangladeshi women of childbearing age consume very small quantities of foods that are important sources of fat, and consequently, small quantities of PUFA.

The total fat and ALA intakes of Bangladeshi mothers, as a percentage of total energy, are estimated to be almost universally less than the respective 20 and $0.5 \%$ minimums recommended by the 2008 Joint WHO/FAO Expert Consultation on Fats and Fatty Acids ${ }^{(5,6)}$. The estimated intake of LA was also below the minimum recommended intake levels in approximately $60 \%$ of women. Approximately, $10 \%$ of the women in our sample may have LA and ALA consumption below the levels considered to be necessary to prevent EFA deficiency. Although it is likely that most women with this low intake would be protected from EFA deficiency by their fat stores, women with low body fat may be at increased risk $^{(35)}$. Also, there should be particular concern for breastfeeding women with this low level of intake, as they are continuously transferring LA and ALA to their children in breast milk, and our BMI data suggest that depleted fat stores may be more common in breast-feeding women. A similar concern might be raised for DHA, as the women in the present study consumed far less DHA than the recommended usual daily intake of $200 \mathrm{mg} / \mathrm{d}$ for lactating women ${ }^{(5,9,36)}$.

Overall, the pattern of fatty acids that we observed in the milk from rural Bangladeshi mothers reflected the dietary patterns in the population. Consistent with the findings in a number of other studies in populations with highcarbohydrate, low-fat diets, we observed a high level of myristic acid (14:0), a medium-chain SFA that is synthesised from acetyl-CoA in the mammary gland ${ }^{(15,37-40)}$. The breast milk from the Bangladeshi mothers also had low levels of oleic (18:1n-9) and stearic (18:0) acids; the concentrations of these fatty acids are generally lower in human milk with increased medium-chain SFA levels ${ }^{(13,16)}$

Levels of LA and ALA in the breast milk from the present study sample were among the lowest reported in the extensive literature characterising breast-milk fatty acid composition. Prentice \& Paul ${ }^{(41)}$ summarised data on the breast milk composition of mothers from separate studies in eight African and South American countries with diets that could be generally characterised as high carbohydrate and low fat. When compared with women from those countries, the women from the present study delivered the lowest median LA levels $(0 \cdot 103 \mathrm{~g} / \mathrm{g}$ fat; range for eight countries: $0 \cdot 110-0 \cdot 238)$ and the second lowest ALA level $(0.003 \mathrm{~g} / \mathrm{g}$ fat; range: $0 \cdot 001-0 \cdot 014)^{(41)}$. Breast-milk LA and ALA levels from the Bangladeshi mothers were also below those observed in mothers from more developed countries ${ }^{(42,43)}$. Human milk from mothers in Nepal, the Philippines, the Congo and Pakistan exhibited comparably low LA levels, but the very low ALA level observed in the breast milk from Bangladeshi women was observed only in milk from the Pakistani women ${ }^{(43-46)}$ As a result of the very low ALA levels, breast milk from the Bangladeshi mothers had a median LA:ALA ratio of 35 , which is much higher than the recommended range of $5-15: 1^{(46)}$. The authors of the studies that included the Filipina and Pakistani mothers both concluded that inadequate LA and ALA intake might be the cause of the low EFA levels in the breast milk $^{(43,44)}$. The present study provides support for this conclusion, as we found that the Bangladeshi women were consuming low levels of EFA compared with international recommendations.

In contrast to the present findings regarding breast-milk LA and ALA, the breast-milk ARA and DHA concentrations for the Bangladeshi mothers fell in the middle of reported ranges for women from many different countries ${ }^{(41-43,45,47,48)}$ The median ARA and DHA percentage weights for breast milk from Bangladeshi mothers were very close to the mean concentrations of DHA (0.32\%) and ARA (0.47\%) that were determined in a descriptive meta-analysis of milk from 2474 women in sixty-five studies ${ }^{(49)}$.

It is possible that regulatory mechanisms play an important role in determining DHA and ARA levels in human milk, as the ARA and DHA levels in the breast milk of the Bangladeshi mothers were maintained at levels that fall near the middle of ranges observed in other populations, despite low intake of fat and prolonged lactation. There are several potential 
mechanisms that could be up- or down-regulated to control breast-milk PUFA content, including the release of fatty acids from lipoproteins by lipase, the transport of fatty acids from the blood into the mammary gland and the synthesis of milk TAG by acyl transferases ${ }^{(16)}$. ARA, in particular, seems to be tightly controlled in breast milk, with a limited range of ARA concentrations observed across populations with very different diets ${ }^{(39,50-52)}$. Future longitudinal studies that examine changes in white adipose tissue or erythrocyte fatty acid composition in mothers over the course of prolonged lactation could help to elucidate these issues.

The low LA intake of the women in the present study may have allowed for increased conversion of ALA to DHA. However, subjects in an intervention trial who consumed a diet with an EFA profile similar to the women in the present study (3\% of energy from LA and $0.4 \%$ of energy from ALA) converted more dietary ALA into EPA but did not increase the absolute amount of DHA synthesised compared with subjects on a control diet ( $7 \%$ of energy from LA and $0.4 \%$ of energy from ALA) ${ }^{(53)}$.

Fish is a regular part of the Bangladeshi diet, but the breastmilk DHA concentrations in the present study were not as high as those observed in other countries where fish is regularly consumed ${ }^{(51)}$. This may be explained by the fact that the vast majority of fish intake was from freshwater fish, which generally contain less DHA than ocean fish. In addition, the estimated amount of usual fish intake was low.

Several limitations of the present study deserve comment. Our observations about the relationship between PUFA intake and breast-milk concentrations would have been strengthened by presenting data on maternal biochemical PUFA status. However, we were unable to collect blood samples from the mothers, and there is no previous data on biochemical PUFA status available for a comparable Bangladeshi population. It is possible that we may have under- or overestimated the percentage of women who would fall below the stated fat intake cut-off values because we collected only $2 \mathrm{~d}$ of dietary data for each individual. However, we improved our estimates for the population intake distribution by using statistical methods to adjust for episodic consumption and remove within-individual variation ${ }^{(28)}$. Although the in-home observations allowed us to collect reliable quantitative data on actual food intake, it is conceivable that our presence may have influenced the women's food consumption on the observation days. However, if the women did include more desirable foods (e.g. oil and animal source foods) in their cooking during our observation days, we may have overestimated their true usual fat intakes. Another potential source of error is that at least one major meal (approximately $22 \%$ of total energy) was generally obtained via recall, as it was consumed outside of the $12 \mathrm{~h}$ observation window. However, we did find that estimated intakes of energy were similar between recalled and observed meals. Additional error may have been introduced when using food composition tables to convert food to nutrients, as the nutrient composition of foods can vary significantly across seasons and geographical regions, and budgetary constraints prevented us from directly analysing foods from the study area to determine fatty acid composition. To partially address this limitation, we have presented quantitative data on food intake to support the nutrient intake data.

\section{Conclusion}

Overall, breast milk from Bangladeshi mothers provides 2448-month-old children with easily absorbed medium-chain SFA, some LA and ALA, and adequate amounts of ARA and DHA. However, prolonged lactation combined with very low fat intake may lead to significant demands on the maternal body pool of fatty acids. Increasing the dietary intake of PUFA in these mothers thus has the potential to positively affect breast milk composition, and consequently, children's health and development. Research into this area needs to consider not only the fatty acid content of breast milk, but also to examine the effects of breast-feeding on maternal fat stores, maternal health outcomes and the amount of fatty acids supplied to subsequent offspring during pregnancy and lactation. Women who are breast-feeding at high frequency for an extended period of time may require greater fat intake to provide the fatty acids for milk and the additional energy needed to prevent lean tissue loss and to promote replenishment of maternal fat stores. Bangladeshi women in general, and especially those who breast-feed for more than 2 years, may benefit from an increased percentage of total energy consumed from lipids and greater intake of food sources of PUFA.

\section{Acknowledgements}

The authors thank the study participants who welcomed us into their homes and the staff from the ICDDR,B who were instrumental to the data collection process. We thank Dr Daniel Tancredi from the University of California (UC) Davis School of Medicine, Department of Pediatrics, for statistical consultation. We are also grateful to Diego Vargas and Andrea Eaton for their invaluable assistance during the laboratory analyses and to Dr Susan Ebeler from UC Davis Department of Viticulture and Enology, for generously allowing us to use the GC in her laboratory. The present study was supported by the Bristol-Myers Squibb Foundation, Inc., the Harvest Plus Challenge Program (coordinated by the Centro Internacional de Agricultura Tropical and the International Food Policy Research Institute), the National Institute of Environmental Health Sciences (NIEHS) grant R37 ES02710, the NIEHS Superfund Basic Research Program P42 ES04699, the UC Davis Center for Children's Environmental Health, NIEHS grant P01 ES11269 and the University of California Discovery Program. None of the authors had any financial or personal interest in the organisations sponsoring the present study. The authors' responsibilities were as follows: E. A. Y. participated in the study design, study implementation, data analysis, interpretation of results and prepared the manuscript; J. E. A. contributed to the study design, study implementation and critical review of the manuscript; M. M. I., M. B. H., A. S. R., T. A., K. M. J. and B. L. L. were involved in the study implementation and critical review of the manuscript; J. B. G. assisted in for funding, interpretation of results 
and critical review of the manuscript; L. A. G. was responsible for method development for the laboratory analysis; C. D. performed the critical review of the manuscript; K. H. B. had the primary responsibility for funding, study design, interpretation of results and critical review of the manuscript.

\section{References}

1. Das UN (2006) Essential fatty acids: biochemistry, physiology and pathology. Biotechnol J 1, 420-439.

2. Innis SM (2007) Dietary ( $n$-3) fatty acids and brain development. J Nutr 137, 855-859.

3. Brown KH, Black RE, Becker S, et al. (1982) Consumption of foods and nutrients by weanlings in rural Bangladesh. Am J Clin Nutr 36, 878-889.

4. Prentice AM \& Paul AA (2000) Fat and energy needs of children in developing countries. Am J Clin Nutr 72, Suppl., 1253S-1265S.

5. Brenna JT \& Lapillonne A (2009) Background paper on fat and fatty acid requirements during pregnancy and lactation. Ann Nutr Metab 55, 97-122.

6. Elmadfa I \& Kornsteiner M (2009) Fats and fatty acid requirements for adults. Ann Nutr Metab 55, 56-75.

7. Holman RT (1960) The ratio of trienoic:tetraenoic acids in tissue lipids as a measure of the essential fatty acid requirement. J Nutr 70, 405-410.

8. Bjerve KS, Fischer S \& Alme K (1987) Alpha-linolenic acid deficiency in man: effect of ethyl linolenate on plasma and erythrocyte fatty acid composition and biosythesis of prostanoids. Am J Clin Nutr 46, 570-576.

9. Koletzko B, Lien E, Agostoni C, et al. (2008) The role of longchain polyunsaturated fatty acids in pregnancy, lactation and infancy: review of current knowledge and consensus recommendations. J Perinat Med 36, 5-14.

10. Salihu HM, Mbah AK, Alio AP, et al. (2009) Low pre-pregnancy body mass index and risk of medically indicated versus spontaneous preterm singleton birth. Eur J Obstet Gynecol Reprod Biol 144, 119-123.

11. Siega-Riz AM, Viswanathan M, Moos MK, et al. (2009) A systematic review of outcome of maternal weight gain according to the Institute of Medicine recommendations: birthweight, fetal growth, and postpartum weight retention. Am J Obstet Gynecol 201, 339.e1-339.e14.

12. Joint $\mathrm{FAO} / \mathrm{WHO} / \mathrm{UNU}$ Expert Consultation (2004) Human energy requirements. http://www.fao.org/docrep/007/y5686e/ y5686e00.HTM (accessed 20 September 2010).

13. Vuori E, Kiuru K, Makinen SM, et al. (1982) Maternal diet and fatty acid pattern of breast milk. Acta Paediatr Scand $\mathbf{7 1}$, 959-963.

14. Hachey DL, Silber GH, Wong WW, et al. (1989) Human lactation II: endogenous fatty acid synthesis by the mammary gland. Pediatr Res 25, 63-67.

15. van Beusekom CM, Martini IA, Rutgers HM, et al. (1990) A carbohydrate-rich diet not only leads to incorporation of medium-chain fatty acids (6:0-14:0) in milk triglycerides but also in each milk-phospholipid subclass. Am J Clin Nutr 52, 326-334.

16. Schmeits BL, VanderJagt DJ, Okolo SN, et al. (1999) Selective retention of $n-3$ and $n-6$ fatty acids in human milk lipids in the face of increasing proportions of medium chain-length (C10:14) fatty acids. Prostaglandins Leukot Essent Fatty Acids 61, 219-224.

17. Vinoy S, Rosetta L \& Mascie-Taylor CGN (2000) Repeated measurements of energy intake, energy expenditure and energy balance in lactating Bangladeshi mothers. Eur $J$ Clin Nutr 54, 579-585.

18. Hels O, Hassan N, Tetens I, et al. (2003) Food consumption, energy and nutrient intake and nutritional status in rural Bangladesh: changes from 1981-1982 to 1995-96. Eur J Clin Nutr 57, 586-594.

19. Alam DS, van Raaij JMA, Hautvast JGAJ, et al. (2003) Energy stress during pregnancy and lactation: consequences for maternal nutrition in rural Bangladesh. Eur J Clin Nutr 57, 151-156.

20. Sarkar NR \& Taylor R (2005) Weight loss during prolonged lactation in rural Bangladeshi mothers. J Health Popul Nutr 23, $177-183$.

21. National Institute of Population Research and Training (NIPORT) \& Mitra and Associates, Macro International (2009) Bangladesh Demographic and Health Survey 2007. Dhaka, Bangladesh and Calverton, MD: National Institute of Population Research and Training, Mitra and Associates, and Macro International.

22. Grais RF, Rose AMC \& Guthman JP (2007) Don't spin the pen: two alternative methods for second-stage sampling in urban cluster surveys. Emerg Themes Epidemiol 4, 8.

23. Arsenault JA, Yakes EA, Hossain MB, et al. (2010) The current high prevalence of dietary zinc inadequacy among children and women in rural Bangladesh could be substantially ameliorated by zinc biofortification of rice. $J$ Nutr 140, 1683-1690.

24. U.S. Department of Agriculture: Agricultural Research Service (2007) Release 20: USDA nutrient database for standard reference. http://www.ars.usda.gov/ba/bhnrc/ndl (accessed 23 August 2009).

25. Kramer EM, Peterson KE, Rogers BL, et al. (1997) Intrahousehold allocation of energy intake among children under five years and their parents in rural Bangladesh. Eur J Clin Nutr 51, 750-756.

26. Ruel MT, Dewey KG, Martinez C, et al. (1997) Variation of single daytime samples of human milk to estimate the 24-h concentration of lipids in urban Guatemalan mothers. $A m \mathrm{~J}$ Clin Nutr 65, 439-444.

27. Folch J, Lees M \& Sloane Stanley GH (1957) A simple method for the isolation and purification of total lipides from animal tissues. J Biol Chem 226, 497-509.

28. Tooze JA, Midthune D, Dodd KW, et al. (2006) A new statistical method for estimating the usual intake of episodically consumed foods with application to their distribution. J Am Diet Assoc 106, 1575-1587.

29. National Cancer Institute (2009) Usual Dietary Intakes: SAS Macros for the NCI Method. Bethesda, MD. http://riskfactor. cancer.gov/diet/usualintakes/macros.html (accessed 27 September 2009).

30. Freedman LS, Guenther PM, Dodd KW, et al. (2010) The population distribution of ratios of usual intake of dietary components that are consumed every day can be estimated from repeated 24-hour recalls. J Nutr 140, 111-116.

31. Shafique S, Akhter N, Stallkamp G, et al. (2007) Trends of under- and overweight among rural and urban poor women indicate the double burden of malnutrition in Bangladesh. Int J Epidemiol 36, 449-457.

32. Dewey KG, Heinig MJ \& Nommsen LA (1993) Maternal weight-loss patterns during prolonged lactation. Am J Clin Nutr 58, 162-166.

33. Butte NF \& King JC (2005) Energy requirements during pregnancy and lactation. Public Health Nutr 8, 1010-1027.

34. Rosetta L, Kurpad A, Mascie-Taylor CGN, et al. (2005) Total energy expenditure (H218O), physical activity level and milk 
output of lactating rural Bangladeshi tea workers and nontea workers. Eur J Clin Nutr 59, 632-638.

35. Hibbeln JR, Nieminen LRG, Blasbalg TL, et al. (2006) Healthy intakes of $n-3$ and $n-6$ fatty acids: estimations considering worldwide diversity. Am J Clin Nutr 83, Suppl., 1483S-1493S.

36. Koletzko B, Cetin I, Brenna JT, et al. (2007) Dietary fat intakes for pregnant and lactating women. Br J Nutr 98, $873-877$

37. Insull W, Hirsch J, James T, et al. (1959) The fatty acids of human milk. II. Alterations produced by manipulation of caloric balance and exchange of dietary fats. J Clin Invest 38, 443-450.

38. Read WWC, Lutz PG \& Tashjian A (1965) The influence of dietary carbohydrates and fat on the fatty acids of mature milk. A study in four ethnic groups. Am J Clin Nutr 17, 180-183.

39. Smit EN, Martini IA, Mulder H, et al. (2002) Estimated biological variation of the mature human milk fatty acid composition. Prostaglandins Leukot Essent Fatty Acids 66, 549-555.

40. Thiombiano-Coulibaly N, Rocquelin G, Eymard-Duvernay S, et al. (2003) Seasonal and environmental effects on breast milk fatty acids in Burkina Faso and the need to improve the omega-3 PUFA content. Acta Paediatr 92, 1388-1393.

41. Prentice AW \& Paul AA (2000) Fat and energy needs of children in developing countries. Am J Clin Nutr 72, 1253S-1265s.

42. Xiang M, Harbige LS \& Zetterstrom R (2005) Long-chain polyunsaturated fatty acids in Chinese and Swedish mothers: diet, breast milk and infant growth. Acta Paediatr 94, 1543-1549.

43. Yuhas R, Pramuk K \& Lien EL (2006) Human milk fatty acid composition from nine countries varies most in DHA. Lipids 41, 851-858.

44. Smit EN, Oelen EA, Seerat E, et al. (2000) Breast milk docosahexaenoic acid (DHA) correlates with DHA status of malnourished infants. Arch Dis Child 82, 493-494.

45. Glew RH, Huang YS, VanderJagt TA, et al. (2001) Fatty acid composition of the milk lipid of Nepalese women: correlation between fatty acid composition of serum phospholipids and melting point. Prostaglandins Leukot Essent Fatty Acids 65, 147-156.

46. Rocquelin G, Tapsoba S, Kiffer J, et al. (2003) Human milk fatty acids and growth of infants in Brazzaville (The Congo) and Ouagadougou (Burkina Faso). Public Health Nutr 6, 241-247.

47. Marangoni F, Agostoni C, Lammardo AM, et al. (2000) Polyunsaturated fatty acid concentrations in human hindmilk are stable throughout 12-months of lactation and provide a sustained intake to the infant during exclusive breastfeeding: an Italian study. Br J Nutr 84, 103-109.

48. Peng YM, Zhang TY, Wang Q, et al. (2007) Fatty acid composition in breast milk and serum phospholipids of health term Chinese infants during first 6 weeks of life. Acta Paediatr 96 , $1640-1645$.

49. Brenna JT, Varamini B \& Jensen RG (2007) Docosahexaenoic and arachidonic acid concentrations in human breast milk worldwide. Am J Clin Nutr 85, 1457-1464.

50. Sanders TAB (1999) Essential fatty acid requirements of vegetarians in pregnancy, lactation and infancy. Am J Clin Nutr 70, Suppl., 555S-559S.

51. Lauritzen L, Jorgensen MH, Hansen HS, et al. (2002) Fluctuations in human milk long-chain PUFA levels in relation to dietary fish intake. Lipids 37, 237-244.

52. Kuipers RS, Fokkema MR, Smit EN, et al. (2005) High contents of both docosahexaenoic and arachidonic acids in milk of women consuming fish from lake Kitangiri (Tanzania) targets for infant formulae close to our ancient diet? Prostaglandins Leukot Essent Fatty Acids 72, 279-288.

53. Goyens PLL, Spilker ME, Zock PL, et al. (2006) Conversion of a-linolenic acid in humans is influenced by the absolute amounts of a-linolenic acid and linoleic acid in the diet and not by their ratio. Am J Clin Nutr 84, 44-53.

54. WHO Expert Consultation (2004) Appropriate body-mass index for Asian populations and its implications for policy and intervention strategies. Lancet 363, 157-163. 